\title{
Vriendschappen tussen jong en oud in 25 Europese landen
}

\author{
Pearl A. Dykstra en Maria Fleischmann ${ }^{12}$
}

Gepubliceerd in Mens \& Maatschappij, 2016, 91(2), 107-131.

\section{Summary \\ Cross-age friendships in 25 European countries}

This paper focuses on individual and country-level circumstances shaping friendships between young and old to gain insight into conditions for intergenerational solidarity. Using European Social Survey data, findings show that relatively few people have cross-age friendships (18\% of the young and $31 \%$ of the old). As predicted by the 'meeting principle', individuals who operate in settings where there are opportunities for meaningful interactions with people belonging to a different age group are more likely to have cross-age friendships. As predicted by the 'disposition principle', individuals with more favourable feelings about other age groups are more likely to have cross-age friendships. Neither the Active Ageing Index nor macro-level trust and individualism show significant associations with the likelihood of having cross-age friendships. Apparently, conditions that bring generations together are meeting opportunities at the local level, underscoring the importance of decentralized initiatives aimed at increased contact and co-operation across age groups.

Keywords: friendship, ageism, age segregation, active ageing, intergenerational solidarity

\section{Inleiding}

Homophily (Lazarsfeld \& Merton, 1954) of homogamy (McPherson, Smith-Lovin, \& Cook, 2001) is het fenomeen dat nauwe banden vooral ontstaan tussen mensen van dezelfde leeftijd, sekse, burgerlijke staat, etniciteit, religie of sociale klasse. Een sociologische verklaring voor dit fenomeen is dat de homogene samenstelling van de omgevingen waarin mensen zich begeven relaties tussen soortgelijken creëert (Huckfeldt, 1983). Een psychologische verklaring is dat de overeenkomst in achtergrondkenmerken, sociale waarden of levensfase het gemakkelijker maakt om met elkaar om te gaan en relaties te vormen (Huston \& Levinger, 1978). Homophily is een grondbeginsel van onderzoek naar persoonlijke relaties en dit is wellicht de reden waarom relaties tussen mensen die niet tot dezelfde sociale categorie behoren onderbelicht zijn gebleven in de literatuur. In het onderhavige onderzoek richten we ons op vriendschappen tussen oud en jong, dus op zogenaamde leeftijdsheterogame relaties. Er is weinig kennis over waar, wanneer en hoe dergelijke relaties ontstaan en voortduren (Riley \&Riley, 2000). Ons inziens is het gebrek aan aandacht voor leeftijdsheterogame relaties een kritische omissie. Een beter begrip van de condities voor betekenisvolle interacties tussen jong en oud geeft inzicht in grondslagen van intergenerationele solidariteit. 
Hagestad en Uhlenberg (2005, 2006; Uhlenberg, 2000) spreken over 'leeftijdssegregatie' om aan te geven dat er in het dagelijks leven grenzen bestaan tussen jong en oud. Mensen brengen een groot deel van hun tijd door in leeftijdsenclaves, ieder met hun eigen cultuur en met op hun leeftijd gerichte bezigheden. Kinderen en jong-volwassenen worden afgezonderd in scholen, volwassenen werken op plekken waar de jongsten en oudsten worden geweerd, en ouderen komen niet zelden terecht in aparte woon- en zorgvoorzieningen. Leeftijdssegregatie wordt geproduceerd en versterkt door wat de 'tripartiete' levensloop wordt genoemd (Kohli, 1988; Riley \& Riley, 1994): de temporele ordening van de levensfases van voorbereiding, gezinsvorming en werk, en pensionering. Tripartisatie komt historisch voort uit de overgang van een economisch systeem van huishoudensproductie naar een stelsel gebaseerd op arbeidsloon, met de daarbij behorende afschaffing van kinderarbeid, uitbreiding van onderwijs en invoering van sociale-zekerheidsarrangementen (Mayer \& Schöpflin, 1989; Kohli, 2007). De chronologisch gestandaardiseerde levensloop heeft sociale orde gecreëerd mede omdat er regels zijn die mensen kunnen volgen bij het vormgeven van hun leven. Die regels komen naar voren in sociaal-gedeelde ideeën over het 'juiste' tijdstip waarop gebeurtenissen zoals uithuisgaan en kinderen krijgen horen plaats te vinden (Liefbroer \& Billari, 2010; Settersten \& Hagestad, 1996a, 1996b; Spéder, Murinkó, \& Settersten, 2014). Daarnaast zijn ze formeel vastgelegd in juridische normen omtrent de rechten en plichten van mensen van verschillende leeftijden (Mayer \& Müller, 1986) en vormen ze de basis voor naar leeftijd ingedeelde onderwijs-, werk- en socialezekerheidsregelingen (Lynch 2006).

Coleman (1982) betoogt dat leeftijdssegregatie enerzijds jongeren de mogelijkheid ontneemt om een goed beeld te krijgen van middelbare en latere levensfasen en anderzijds ouderen creëert die weinig affiniteit hebben met jongere generaties. In zijn visie kan leeftijdssegregatie zowel oorzaak als gevolg zijn van leeftijdsvooroordelen, in het Engels aangeduid als ageism (Butler 1969). Scheidingen tussen leeftijdsgroepen kunnen vooroordelen doen ontstaan maar deze ook versterken. De vooroordelen, op hun beurt, kunnen grenzen aanbrengen tussen jong en oud. Uit klassiek sociologische studies weten we dat gescheiden werelden de ideale condities zijn voor het ontstaan en voortbestaan van stereotype ideeën en opvattingen over 'de ander'. Het neerhalen van leeftijdsbarrières en het scheppen van mogelijkheden voor interacties tussen jong en oud zouden effectieve manieren kunnen zijn om sociale segmentatie te reduceren en meer cohesie in de samenleving te realiseren (Hagestad \& Uhlenberg, 2005, 2006).

Leeftijdssegregatie is minder sterk wanneer oud en jong zich op dezelfde plekken bevinden en veel mogelijkheden hebben om langdurige contacten aan te gaan (Vanderbeck 2007). Volgens Uhlenberg (2000) zijn sommige samenlevingen meer leeftijdsinclusief dan andere. In zijn visie moet er onderzoek worden gedaan naar de formele en informele condities die ervoor zorgen dat oud en jong elkaar ontmoeten, met elkaar samenwerken, van elkaar leren, en elkaar beter leren kennen. Wij volgen Uhlenbergs advies en richten ons op de vraag welke micro- en macrocondities betekenisvolle interacties tussen oud en jong faciliteren. Meer in het bijzonder kijken we naar leeftijdsheterogame vriendschappen. We onderzoeken de rol van 
determinanten zowel op het individuele niveau als op het landniveau. We maken gebruik van de vierde ronde van het European Social Survey (ESS), dat een speciale module had over leeftijdsvooroordelen, ontwikkeld door Abrams, Lima en Coudin (2007). Deze module richt zich specifiek op twee leeftijdsgroepen: ouderen boven de 70 en twintigers. We onderzoeken de generatie-overstijgende contacten die deze twee groepen hebben en richten ons specifiek op de vriendschappen die jongeren (18-30 jaar) hebben met ouderen (70-90 jaar), en vice versa.

\section{Condities voor vriendschappen tussen oud en jong ${ }^{3}$}

\section{Individueel niveau}

Een centrale gedachte binnen onderzoek naar persoonlijke relaties is dat er no mating without meeting is (Blau, 1977; Fischer, 1982; Verbrugge, 1977): mensen vinden vrienden en partners onder degenen die ze tegenkomen in de loop van hun dagelijkse activiteiten. Dit ontmoetingsbeginsel benadrukt dat omgevingen mogelijkheden bieden om bepaalde categorieën individuen te ontmoeten en op die manier van invloed zijn op relaties die worden ontwikkeld. Als we dit beginsel toepassen, dan kunnen we verwachten dat degenen die een naar leeftijd gemêleerd aanbod aan contacten beschikken, vaker leeftijdsheterogame vriendschappen zullen hebben.

Families vormen een van de weinige omgevingen waarin mensen van verschillende leeftijden met elkaar omgaan. Hagestad en Uhlenberg (2005, p. 354) betogen zelfs dat 'the family represents the only truly age-integrated social institution' (cursivering in originele tekst). Volgens hen hebben goed-functionerende familiebanden onderscheidende kenmerken zoals wederzijdse ondersteuning, langdurig contact, emotionele complexiteit, gedeelde identiteit en inlevingsvermogen, die ertoe bijdragen dat mensen meer open voor 'anderen' worden. Duurzame interacties in families resulteren in een beter begrip van mensen van verschillende leeftijden en daarmee, zo is de veronderstelling, ook een positieve grondhouding voor relaties met oud en jong buiten de eigen familie. Empirische steun voor de gedachte dat intergenerationele familieervaringen gegeneraliseerd worden andere leden van de betreffende leeftijdsgroepen komt uit onderzoek naar grootouderschap. Jongeren die goede contacten onderhouden met hun grootouders blijken positiever over ouderen te denken dan jongeren die dergelijke contacten ontberen (Harwood, Hewstone, Paolini, \& Voci, 2005; Tam, Hewstone, Harwood, Voci, \& Kenworthy, 2006). Op basis van de voorgaande overwegingen formuleren we de volgende hypothese (H1): degenen die goede banden onderhouden met familieleden die veel jonger of veel ouder zijn dan zijzelf, hebben een grotere kans om leeftijdsheterogame vriendschappen te hebben dan degenen die dergelijke banden niet hebben. Let wel: het gaat steeds om vriendschappen buiten de familie.

Weinig is bekend over het aandeel jongeren dat regelmatige contacten heeft met ouderen buiten de familie, die voor betrokkenen een bron van hulp, bemoediging en advies zijn (Hagestad 2008). Voorbeelden van omgevingen voor intergenerationele interacties buiten de familie zijn 
godsdienstige gemeenschappen (Evans, 2011; Grefe, 2011), betaald werk, (Uhlenberg, 2000), vrijwilligerswerk (Uhlenberg \& De Jong Gierveld, 2004), en buurten (Vanderbeck 2007). Of dergelijke omgevingen de vorming van leeftijdsheterogame relaties inderdaad bevorderen, is nauwelijks onderzocht. In zoverre studies rond dit thema zijn verricht, hebben ze het perspectief van de oudere generaties gehanteerd (Uhlenberg \& De Jong Gierveld, 2004), niet dat van de jongere. Dit brengt ons tot de volgende hypothese $(\mathrm{H} 2)$ : degenen met dagelijkse activiteiten in omgevingen buiten de familie die hen in staat stellen om mensen te ontmoeten die veel jonger of veel ouder zijn dan zijzelf, hebben een grotere kans om leeftijdsheterogame vriendschappen te hebben dan degenen die dergelijke activiteiten niet hebben. De omgevingen buiten de familie die we in beschouwing nemen, zijn: betaald werk, vrijwilligerswerk en religieuze gemeenschappen.

Eerder hebben we betoogd dat goede intergenerationele contacten in de familie mensen ontvankelijker maken voor intergenerationele contacten buiten de familie. Het onderliggende mechanisme zou zijn dat mensen positiever staan tegenover anderen die sterk in leeftijd verschillen. Echter, het kan niet worden uitgesloten dat leeftijdsheterogame vriendschappen ontstaan via de goede intergenerationele contacten in de familie. Vandaar dat we naar de tweede verklaring gaan die in de literatuur is te vinden voor verschillen in de samenstelling en omvang van persoonlijke netwerken (Fischer \& Oliker, 1983; Mollenhorst, Völker, \& Flap, 2008). Deze richt zich op disposities: mensen gaan relaties aan op basis van hun voorkeuren, die weer voortkomen uit eerdere ervaringen. Als we dit beginsel toepassen, dan kunnen we verwachten dat degenen die op basis van opvoeding en ondervinding sterker openstaan voor leeftijdsdiversiteit, vaker intergenerationele contacten zullen onderhouden. We toetsen de volgende hypothese (H3): degenen die meer positieve gevoelens hebben voor mensen die veel jonger of veel ouder zijn dan zijzelf hebben een grotere kans om leeftijdsheterogame vriendschappen te hebben.

Hoewel disposities vrije keuze suggereren, moet het belang van externe restricties niet worden genegeerd. Fischers (1982) choice-constraint benadering van persoonlijke netwerken stelt dat mensen ervoor kiezen om vriendschappen aan te gaan en te onderhouden binnen de restricties van structurele omstandigheden zoals vrij-beschikbare tijd, financiële hulpbronnen en geografische nabijheid. Fischer benadrukt dat disposities niet altijd tot uiting komen in daadwerkelijk relatiegedrag. De voorkeuren kunnen verborgen zijn vanwege structurele beperkingen om relaties te vormen. Geïnspireerd door Fischers inzichten, komen we tot een aanvullend perspectief voor onze studie, namelijk dat de mate waarin een naar leeftijd gemêleerd aanbod aan contacten leidt tot aangaan en onderhouden van leeftijdsheterogame vriendschappen mede bepaald wordt door iemands disposities. Dit brengt ons tot de volgende hypothese (H4): degenen in omgevingen met een leeftijdsdivers aanbod van contacten hebben een nog grotere kans om leeftijdsheterogame vriendschappen te hebben dan degenen die dergelijke activiteiten niet hebben als zij positieve gevoelens hebben voor mensen die veel ouder of veel jonger zijn dan zijzelf.

\section{Landniveau}


Naast microcondities richten we ons op de rol van macrocondities die de mogelijkheden en voorkeuren voor interacties tussen oud en jong vorm kunnen geven. Een eerste voorbeeld betreft nationaal beleid gericht op voorzieningen, diensten en financiële tegemoetkomingen voor specifieke leeftijdsgroepen. Dergelijk beleid moedigt niet alleen aan dat geselecteerde leeftijdsgroepen op afstand worden geplaatst (bijvoorbeeld ouderen in aparte woonvoorzieningen, kinderen en jongeren op scholen) maar mogelijk ook dat zij op een vooringenomen manier worden gepercipieerd. Binstock (1983) introduceerde het begrip compassionate ageism als aanduiding voor de wijze waarop beleid de opvatting reflecteert of juist bevordert dat specifieke leeftijdsgroepen, zoals ouderen en jongeren, noden hebben die met behulp van publieke middelen moeten worden gelenigd. Dit mededogen vanuit de overheid zou bij de bevolking gevoelens van sympathie voor de oudsten en de jongsten creëren. In een latere publicatie schreef Binstock (2010) over 'double-edged' compassionate ageism. Hij bedoelt hiermee dat overheidssteun voor ouderen genereus lijkt, maar ook negatieve stereotyperingen van kwetsbaarheid, armoede en afhankelijkheid bevestigt (voor vergelijkbare beschouwingen, zie Townsend, 2006; Walker 2000). Samenvattend constateren we dat beleid gericht op specifieke leeftijdsgroepen zowel positieve als negatieve implicaties kan hebben voor interacties tussen jong en oud.

Wetgeving die de rechten en plichten van mensen uit verschillende leeftijdsgroepen definieert, is een tweede voorbeeld van de wijze waarop macrocondities de verhoudingen tussen oud en jong structureren. Te denken valt aan wetten tegen leeftijdsdiscriminatie, waarin dominante waarden over 'juiste' leeftijdsverhoudingen zijn neergelegd. Logischerwijs zullen er meer interacties tussen oud en jong zijn in samenlevingen die gelijke behandeling van mensen van alle leeftijden nastreven dan in samenlevingen waar die vorm van gelijkheid niet wordt gepropageerd ( $c f$. Rippon, Zaninotto, \& Steptoe, 2015). In de Europese Unie is er sinds 2006 een dwingende leidraad die discriminatie op grond van leeftijd verbiedt (Lahey, 2010). Sommige lidstaten hebben echter pas recent hun wetgeving aan de betreffende richtlijn aangepast, terwijl andere van oudsher al wetten tegen leeftijdsdiscriminatie hadden (Ius Laboris, 2010). Naast de vele overeenkomsten tussen Europese landen in de wetten tegen leeftijdsdiscriminatie, is er een grote variëteit aan uitzonderingsbepalingen en nalevingsmechanismen (Ius Laboris 2010), hetgeen landenvergelijkingen op basis van wetgeving complex maakt.

De weergave van leeftijdsgroepen in media en reclame vormt een derde voorbeeld van de wijze waarop hun zichtbaarheid en aantrekkelijkheid via het macroniveau worden beïnvloed. Lepianka (2015) gebruikt de term othering, de benadrukking van het anders-zijn, voor de constructie van beelden van jong en oud in de media. Onderzoek uit diverse landen toont aan dat ouderen in het algemeen en oudere vrouwen in het bijzonder ondervertegenwoordigd zijn in televisieseries en -reclames (Kessler, Rakoczy, \& Staudinger, 2004; Roy et al. 1997). In tegenstelling tot de bewering van sommige critici dat ouderen vooral negatief worden geportretteerd (Abrams, Eveland, \& Giles, 2003), toont een cross-nationaal overzicht dat ouderen relatief gunstig worden afgebeeld in tijdschrift- en televisiereclames (Zhang et al., 
2006). Mogelijk is hier sprake van pogingen van adverteerders om de belangstelling van oudere consumenten te wekken. Samenvattend constateren we dat voor zover ouderen zichtbaar zijn in de media, er niet een eenduidig positief of negatief beeld van hen overheerst.

De hiervoor beschreven voorbeelden dienen om de complexiteit en diversiteit aan macroinvloeden op interacties tussen oud en jong te illustreren. Helaas kunnen we de invloed van de beschreven macrocondities als zodanig niet goed toetsen. Voor beleidsmaatregelen gericht op specifieke leeftijdsgroepen en voor representaties in de media zijn zowel negatieve als positieve effecten te verwachten en het is niet op voorhand duidelijk hoe deze kunnen worden ontrafeld. Cross-nationaal vergelijkende gegevens voor de toepassing van wetgeving tegen discriminatie op grond van leeftijd ontbreken. Datzelfde geldt voor de wijze waarop ouderen en jongeren in de media worden afgebeeld. Vandaar dat we een andere strategie volgen.

Ten eerste richten we ons op de Active Ageing Index (AAI), die de gerealiseerde en potentiële participatie van ouderen in Europese landen weergeeft (Zaidi et al., 2013). We gebruiken de AAI als een geaggregeerde raming voor de wijze waarop factoren zoals beleid, wetgeving, en media leeftijdsgrenzen produceren en reflecteren. De AAI is een instrument dat onderschrijft dat de levens van mensen onder de invloed staan van een complex aan beleidsmaatregelen en jurisdicties (cf. Campbell, 2012). De AAI is in 2012 ontwikkeld in het kader van het Europese Jaar voor Actief Ouderworden en Intergenerationele Solidariteit. ${ }^{4}$ De doelstelling was om een breder perspectief op het functioneren van ouderen te hanteren dan de gebruikelijke 'productivistische' gerichtheid op langer doorwerken (cf. Foster \& Walker, 2015). De AAI erkent de bijdragen van ouderen aan de samenleving (bijvoorbeeld vrijwilligerswerk, mantelzorg, en zorg voor kleinkinderen) en identificeert de condities voor actief ouderworden (bijvoorbeeld opleidingsniveau en resterende levensverwachting). Wij betogen dat landen die hoog op de AAI scoren, en dus grote groepen zichtbare en actieve ouderen herbergen, op macroniveau de structurele condities hebben gecreëerd die interacties tussen oud en jong bevorderen. De actieve participatie van ouderen en hun fysieke aanwezigheid in het openbare leven vergroten de mogelijkheden voor betekenisvolle intergenerationele interacties. De hypothese die we toetsen is (H5): naarmate landen een hogere score op de Active Ageing Index hebben, is de kans dat mensen leeftijdsheterogame vriendschappen hebben groter.

Ten tweede richten we ons op het culturele klimaat van samenlevingen. Eerder hebben we naar voren gebracht dat disposities gericht op leeftijdsdiversiteit gevormd worden in de opvoeding en persoonlijke ervaringen. Hier benadrukken we dat dergelijke disposities ook worden gecreëerd en bevestigd in de bredere context van de maatschappij. We gaan ervan uit dat het aangaan en onderhouden van relaties met mensen die behoren tot een andere sociale categorie zoals klasse, etniciteit, sekse, religie en leeftijd een uiting is van autonomie en authenticiteit. Dergelijk gedrag is eerder te verwachten in individualistische samenlevingen, waar mensen worden geacht zelf vorm en inhoud te geven aan hun leven dan in collectivistische samenlevingen waar mensen sociale waardering ontlenen aan het eerbiedigen van tradities en het nastreven van harmonie (cf. Allik \& Realo, 2004). Aanvullend beschouwen we het aangaan en onderhouden van niet-homogame relaties als het afwijken van sociaal-gedeelde regels, die 
immers contacten met gelijken voorschrijven. Afwijkend gedrag is eerder te verwachten in landen waar mensen een hoge mate van vertrouwen in anderen hebben dan in landen waar argwaan en achterdocht sterker de boventoon voeren (Dehey \& Newton, 2015). We komen tot de volgende hypothese: naarmate landen sterker gekenmerkt zijn door individualisme en sociaal vertrouwen, is de kans dat mensen leeftijdsheterogame vriendschappen hebben groter (H6a en H6b).

\section{Overige determinanten}

Het meeste onderzoek laat zien dat vrouwen grotere en meer diverse netwerken hebben dan mannen (Antonucci, 2001), maar de patronen zijn niet altijd even scherp. Genderverschillen in persoonlijke netwerken verschillen afhankelijk van leeftijd, levensfase en huwelijksgeschiedenis (Ajrouch, Blandon, \& Antonucci, 2005; Fischer \& Oliker, 1983; Van Tilburg, 1995). Daarom houden we in onze analyses rekening met geslacht, leeftijd en partner status. We houden ook rekening met het voltooide opleidingsniveau en met zelf-gerapporteerde gezondheid vanwege mogelijke invloeden van selectie. Opleiding speelt immers een cruciale rol in de ontwikkeling van sociaal kapitaal (Huang, Maassen van den Brink, \& Groot, 2009). Hoe gezond iemand is, bepaalt mede of netwerkrelaties worden aangegaan of worden ontbonden, of dat netwerken specifieke kenmerken krijgen (Smith \& Christakis, 2008). Gegeven dat er zo weinig bekend is over leeftijdshomogame vriendschappen, zijn mogelijke verschillen naar achtergrondkenmerken ook vanuit beschrijvend oogpunt van belang.

Daarnaast controleren we op het macro-niveau voor het Brutonationaal Product (BBP) per capita om de welvaart en economische ontwikkeling in een land in kaart te brengen. Het BBP per capita vertoont een positieve samenhang met vertrouwen op nationaal niveau (Delhey \& Newton, 2005) en met de mate van individualisme in een land (Hofstede, Hofstede, \& Minkov, 2010). Ook is er een positieve samenhang met de Active Ageing Index (UNECE/ European Commission, 2015).

\section{Methoden}

\section{Data}

Ter beantwoording van onze onderzoeksvraag maken we gebruik van de vierde ronde van het European Social Survey (ESS), uitgevoerd in 2008-2009. De vierde ronde heeft data uit 31 landen, waarvan er 25 lid zijn van de Europese Unie (EU). Italië, Malta en Luxemburg zijn geen deelnemers van het ESS. Onze analyses betreffen de $25 \mathrm{EU}$ landen. Het steekproefkader van het ESS wordt gevormd door personen van 15 jaar of ouder in privéhuishoudens. Hoewel de beoogde respons 70 procent is, vertonen de deelnemende landen grote verschillen in responsrealisatie. De respons is het laagst in Kroatië (45,7\%) en het hoogst in Portugal (75,7\%). De surveydata zijn verrijkt met landindicatoren om de macrocondities te onderzoeken die 
leeftijdsheterogame interacties bevorderen: de Active Ageing Index (AAI) die online beschikbaar is, geaggregeerd vertrouwen en geaggregeerd individualisme (beide gebaseerd op ESS data).

\section{Meetinstrumenten}

Of iemand leeftijdsheterogame vriendschappen heeft is gemeten aan de hand van de vraag 'Hoeveel vrienden heeft $\mathrm{u}$ ongeveer die jonger dan 30 zijn [ouder zijn dan 70], uw familieleden niet meegerekend?' De antwoordcategorieën waren 'geen' (1), '1' (2), '2-5' (3), '69' (4), en '10 of meer' (5). Voor de analyses hebben we deze variabele gedichotomiseerd, waarbij respondenten de waarde één kregen als ze twee of meer leeftijdsheterogame vriendschappen hadden.

------ Tabel 1 ongeveer hier ------

Beschrijvende kenmerken van determinanten op het individuele niveau zijn weergegeven in Tabel 1. We gebruiken een reeks dummyvariabelen voor de omgevingsfactoren die leeftijdsheterogame vriendschappen bevorderen. De eerste is of de jongere [oudere] respondent een huisgenoot heeft die 70 jaar of ouder is [tussen de 18 en 30 is] ( $1=$ ja). Aangezien duurzaam contact, emotionele complexiteit en inlevingsvermogen een beter begrip tussen leeftijdsgroepen kunnen genereren, nemen we ook mee of de jong-volwassene [de oudere] een familielid boven de leeftijd van 70 [kinderen of kleinkinderen] heeft waarmee 'sommige persoonlijke kwesties, zoals gevoelens, meningen of ervaringen' kunnen worden besproken $(1=\mathrm{ja})$. Het bijwonen van religieuze diensten is met de volgende vraag gemeten: 'Afgezien van speciale gelegenheden zoals huwelijken of begrafenissen, hoe vaak gaat u tegenwoordig naar religieuze diensten?'. Ook hier is het antwoord gedichotomiseerd waarbij de waarde één betekent dat de respondent 'ten minste 1 keer per maand' religieuze diensten bijwoont. De vraag 'Heeft $\mathrm{u}$ in de afgelopen maand betaalde arbeid of vrijwilligerswerk verricht? Indien ja: Was dat alleen betaalde arbeid, alleen vrijwilligerswerk of beide?' is gebruikt om een dummyvariabele aan te maken die aangeeft of respondenten in de laatste maand betaalde arbeid, vrijwilligerswerk of beide hebben verricht $(1=\mathrm{ja})$. Een nadeel van deze vraag is dat zij niet aangeeft wat de leeftijdssamenstelling is van de werkomgeving. We hebben daarom een dummyvariabele toegevoegd die aangeeft of respondenten 'Een klein deel van de tijd', 'het merendeel van de tijd' of 'alle/bijna alle tijd' met een collega of collega-vrijwilliger van in de 20 [ouder dan 70] hebben gewerkt ( $1=$ ja).

Gevoelens voor mensen die behoren tot een veel jongere of oudere leeftijdsgroep hebben we gemeten aan de hand van de volgende vraag: "Kunt $\mathrm{u}[\ldots]$ zeggen hoe positief of negatief uw gevoelens zijn voor 20ers [mensen ouder dan 70]?”. De mogelijke antwoordcategorieën waren 0 'uiterst negatief' tot 10 'uiterst positief'.

Als meting van de macro-structurele condities die leeftijdsheterogame interacties bevorderen, hanteren we de Active Ageing Index (AAI). De waarden uit 2010 zijn verkregen via de AAI website. ${ }^{5}$ Deze zijn gebaseerd op verschillende cross-nationaal vergelijkende surveys (bijvoorbeeld EU Labour Force Survey, European Quality of Life Survey, EU Statistics of Income and Living Conditions) die in of rond 2008 zijn uitgevoerd, het jaar waarin ook de vierde 
ronde van de ESS heeft plaatsgevonden. De AAI wordt in percentages uitgedrukt, waarbij de waarden van 0 (minimale doelstelling) tot 100 (maximale doelstelling) lopen. Opgemerkt moet worden dat het maximale doelpunt niet gelijk gesteld moet worden aan een optimum omdat een waarde van 100 alleen mogelijk is onder utopische omstandigheden (Zaidi et al., 2013). De gemiddelde AAI voor de 25 landen die hier zijn bestudeerd is 32,3 (zie Tabel 2), waarbij de laagste AAI in Hongarije is gemeten en de hoogste in Zweden. We hebben de AAI gecentreerd rond het gemiddelde voor een meer betekenisvolle modelinterpretatie.

------ Tabel 2 ongeveer hier ------

Voor het culturele klimaat hanteren we landindicatoren van individualisme en sociaal vertrouwen. Hiervoor hebben we de betreffende individuele metingen voor de volledige ESSsteekproeven geaggregeerd naar het landenniveau. De vraag naar vertrouwen was: 'Denkt $\mathrm{u}$, in het algemeen, dat de meeste mensen te vertrouwen zijn, of dat je niet voorzichtig genoeg kunt zijn in de omgang met mensen?'. Respondenten konden een antwoord geven van 0 tot 10, waarbij de waarde 0 staat voor 'Je kunt niet voorzichtig genoeg zijn' en de waarde 10 staat voor 'De meeste mensen zijn te vertrouwen'. Het gemiddelde vertrouwen voor alle landen is 4,79 (zie Tabel 2). Het vertrouwen varieert van 3,43 in Bulgarije tot 6,92 in Denemarken. Voor individualisme is een set van zes items gebruikt. De respondent werd gevraagd om aan te geven in welke mate eigenschappen zoals 'nieuwe ideeën bedenken en creatief zijn, dingen op eigen, originele manier doen' en 'zelf beslissingen nemen, onafhankelijk van anderen zijn' op hem/haar van toepassing waren. Antwoorden varieerden van 'lijkt heel erg veel op mij' (1) tot 'lijkt helemaal niet op mij' (6). De codering van de items is omgedraaid zodat waarden van de schaal uiteindelijk variëren uiteindelijk van 0 (zeer weinig individualistisch) tot 5 (zeer individualistisch). De zes items vormen een intern consistente schaal (Cronbach's Alpha=0,778). De gemiddelde score voor individualisme over de 25 landen heen is 2,97 (zie Tabel 2). Het minst individualistische land is Litouwen $(2,58)$ en het meest individualistische land is Griekenland $(3,54)$.

We gebruiken vijf controlevariabelen om ermee rekening te houden dat vriendschappen kunnen variëren tussen personen. In de analyses is gecontroleerd voor geslacht $(1=$ vrouw), leeftijd (in jaren), opleiding (in jaren), en partner status ( $1=$ woont samen met echtgeno(o)t(e)/partner) en gezondheid. Opleiding betreft het aantal jaren dat iemand een voltijdse opleiding heeft gevolgd sinds de leeftijd van zes jaar. Alle personen die aangaven 26 of meer jaren opleiding te hebben gevolgd (minder dan 0,5 procent) hebben de score 26 jaren opleiding gekregen. Gezondheid is gemeten met de vraag 'Hoe is uw gezondheid in het algemeen?' De antwoordcategorieën varieerden van 'heel erg goed' (1) tot 'heel erg slecht' (5). De codering van de antwoordcategorieën is omgedraaid zodat hogere waarden een betere gezondheid weergeven.

Als controle voor de economische welvaart in een land hebben we het Bruto Binnenlands Product (BBP) per capita van 2008 in onze analyses opgenomen. Het BBP is gemeten in termen van koopkrachtpariteit en wordt relatief uitgedrukt, namelijk gerelateerd aan het gemiddelde BBP van de EU-28 landen. De data zijn afkomstig van Eurostat. Landen waar het BBP per capita 
lager is dan het EU-28 gemiddelde BBP hebben een waarde die lager is dan 100, en landen die een BBP hebben die hoger is dan het EU-28 gemiddelde hebben een waarde die hoger is dan 100. We hebben de maat gecentreerd op nul door 100 af te trekken van het BBP per capita om een meer betekenisvolle modelinterpretatie te verkrijgen. Zoals Tabel 2 laat zien is het BBP per capita het laagst in Bulgarije (-56) en het hoogst in Nederland (+39).

Analyses

De analyses zijn apart uitgevoerd voor $18-30$ jarigen $(\mathrm{N}=8560)$ en $70-90$ jarigen $(\mathrm{N}=$ 6411). Aangezien we informatie van micro- en macroniveau van 25 landen combineren, maken we gebruik van multiniveau logistische regressieanalyse om de kansen te berekenen dat respondenten twee of meer leeftijdsheterogame vriendschappen hebben. Het basismodel is een leeg model zonder voorspellers om de varianties op de verschillende niveaus te bepalen (Tabel 4, Model 0). In de volgende stap voegen we, ter toetsing van de hypothesen 1, 2 en 3, alle individuele voorspellers toe (Tabel 4, Model 1). In aparte analyses, ter toetsing van hypothese 4, onderzoeken we interacties tussen de omgevingsfactoren die leeftijdsheterogame vriendschappen bevorderen en de gevoelens voor mensen die behoren tot een veel jongere of oudere leeftijdsgroep. Tot slot, ter toetsing van de hypothesen 5 en 6, voegen we de landenvariabelen toe aan het model met de individuele voorspellers (Tabel 5). De resultaten worden in Odds Ratios (OR, geëxponentieerde coëfficiënten) weergegeven. Een OR met een waarde boven 1 geeft een positief verband weer, een OR onder 1 een negatief verband.

\section{Resultaten}

In alle landen is te zien dat jongeren minder vaak leeftijdsheterogame vriendschappen rapporteren dan ouderen, respectievelijk $18 \%$ en $31 \%$. Het aandeel jongeren met twee of meer leeftijdsheterogame vriendschappen is het laagst in Litouwen (4\%) en het hoogst in Ierland (36\%) (zie Tabel 3). Het aandeel ouderen met twee of meer heterogame vriendschappen is het laagst in Litouwen (5\%) en het hoogst in Finland (51\%).

------ Tabel 3 ongeveer hier ------

\section{Determinanten op individueel niveau van leeftijdsheterogame vriendschappen}

Zoals Tabel 4 laat zien, is de kans dat jongeren twee of meer vriendschappen met personen boven de 70 hebben hoger als hun dagelijkse activiteiten plaats vinden in een omgeving die mogelijkheden schept voor intergenerationele contacten. Als jongeren een huisgenoot hebben van boven de 70, persoonlijke kwesties bespreken met een familielid van boven de 70, minimaal maandelijks religieuze diensten bijwonen en/of met ouderen betaalde arbeid of vrijwilligerswerk verrichten, is de kans significant hoger dat zij leeftijdsheterogame vriendschappen rapporteren dan als ze niet in deze omstandigheden verkeren. Het verrichten van betaalde arbeid of vrijwilligerswerk in de afgelopen maand is de enige factor die geen grotere kans biedt op het hebben van leeftijdsheterogame vriendschappen wanneer met de overige kenmerken rekening 
wordt gehouden. De odds om meer dan twee leeftijdsheterogame vriendschappen te hebben zijn een factor 1,4 hoger voor jongeren met een oudere huisgenoot en een factor 1,7 hoger voor jongeren die persoonlijke kwesties met een familielid boven de 70 bespreken. Daarnaast zijn de odds om meer dan twee leeftijdsheterogame vriendschappen te hebben een factor 1,6 hoger voor jongeren die minimaal maandelijks religieuze diensten bijwonen en een factor 2,7 hoger voor jongeren die samenwerken met iemand boven de 70 . Ook blijkt dat de kans toeneemt dat jongeren leeftijdsheterogame vriendschappen hebben, naarmate zij meer positieve gevoelens hebben voor 70-plussers.

\section{------ Tabel 4 ongeveer hier ------}

De resultaten voor de oudere respondenten vertonen grote overeenkomsten met die voor de jongere leeftijdsgroep. Het bijwonen van religieuze diensten verhoogt de kans om leeftijdsheterogame vriendschappen te rapporteren: de odds ervoor zijn een factor 1,4 hoger. Daarnaast blijkt dat ouderen die de afgelopen maand betaald werk of vrijwilligerswerk hebben verricht, een factor 1,4 hogere odds hebben om leeftijdsheterogame vriendschappen te rapporteren. Bij ouderen die de afgelopen maand met twintigers hebben gewerkt, zijn de odds om leeftijdsheterogame vriendschappen te hebben een factor 1,9 hoger. Wederom is het zo dat positieve gevoelens voor de andere leeftijdsgroep, in dit geval tegen jongeren, de kans verhoogt om leeftijdsheterogame vriendschappen te hebben (factor 1,1 hoger). De kans om twee of meer leeftijdsheterogame vriendschappen te hebben, zijn niet-significant hoger voor degenen met een huisgenoot onder de 30. Het hebben van een (klein)kind met wie persoonlijke kwesties kunnen worden besproken, blijkt ook geen verschil te maken wat betreft de kans om leeftijdsheterogame vriendschappen te hebben.

Concluderend, we vinden bevestiging voor hypothesen 1, 2 en 3 . We vinden echter geen steun voor hypothese 4 (resultaten niet gerapporteerd in een tabel). Geen van de interacties tussen de omgevingsfactoren die leeftijdsheterogame vriendschappen bevorderen en de gevoelens voor mensen die behoren tot een veel jongere of oudere leeftijdsgroep blijkt significant te zijn. Aldus bieden onze resultaten geen aanwijzing dat omgevingen binnen en buiten de familie met een leeftijdsdivers aanbod van contacten een nog sterkere basis vormen voor het aangaan en onderhouden van leeftijdsheterogame vriendschappen als mensen positief aankijken tegen andere leeftijdsgroepen.

Het onderste blok van Tabel 4 laat zien in hoeverre de kans op het hebben van heterogame vriendschappen verschilt naar achtergrondkenmerken. Onder jongeren maken leeftijd, opleidingsjaren en gezondheid geen verschil in de prevalentie van leeftijdsheterogame vriendschappen. Wel blijkt dat jonge vrouwen minder vaak leeftijdsheterogame vriendschappen rapporteren dan jonge mannen (de odds zijn een factor 0,8 lager). Jongeren die met een partner samenwonen blijken vaker leeftijdsheterogame vriendschappen te rapporteren dan alleenstaanden (de odds zijn een factor 1,2 hoger). Onder de groep oudere respondenten blijken alle achtergrondkenmerken een verschil te maken wat betreft de kans om leeftijdsheterogame vriendschappen te hebben. Oudere vrouwen hebben minder vaak leeftijdsheterogame vriendschappen dan hun mannelijke leeftijdsgenoten (de odds zijn een factor 0,8 lager) en de 
odds om leeftijdsheterogame vriendschappen te hebben nemen onder ouderen af met toenemende leeftijd. Daarnaast hebben ouderen met een hogere opleiding, met een partner in het huishouden en met een betere gezondheid hogere odds om leeftijdsheterogame vriendschappen te rapporteren.

\section{Determinanten op landniveau van leeftijdsheterogame vriendschappen}

De intra-class correlaties die in Tabel 4 worden gerapporteerd tonen aan dat tussen 7 en 8 procent van de variantie in de rapportage van leeftijdsheterogame vriendschappen is toe te schrijven aan landverschillen. De macro-structurele en macro-culturele condities in onze analyses blijken hiervoor echter geen verklaring te bieden (zie Tabel 5). Zowel voor de ouderen als ook voor de jongeren geldt dat geen van de landindicatoren significant gerelateerd is aan de kans om leeftijdsheterogame vriendschappen te hebben. Onze verwachting was dat we verhoogde kansen zouden vinden voor leeftijdsheterogame vriendschappen in landen met hogere scores op de Active Ageing Index en met hogere niveaus van individualisme en sociaal vertrouwen. We vinden echter geen bevestiging van hypothesen 5 en 6 .

$$
\text { Tabel } 5 \text { ongeveer hier ------ }
$$

\section{Conclusies en discussie}

De banden die mensen met anderen hebben, en de netwerken waarvan zij deel uitmaken, spelen een cruciale rol in de bevordering van cohesie in de samenleving. Duurzame contacten tussen mensen uit verschillende sociale categorieën (bijvoorbeeld sociale klasse, religie, sekse, leeftijd, etniciteit, ras en opleidingsniveau) bieden mogelijkheden om 'wij versus zij' onderscheiden te doorbreken. Startend vanuit de premisse dat contact tussen groepen, onder de juiste voorwaarden, een effectieve manier is om vooroordelen te bestrijden (Pettigrew, 1998; Pettigrew \& Tropp, 2006), hebben we gekeken naar condities die vriendschappen tussen mensen van verschillende leeftijd mogelijk maken om inzicht te verkrijgen de wijze waarop intergenerationele solidariteit beter zou kunnen worden ontwikkeld. Weinig studies zijn verricht naar contacten tussen oud en jong buiten de familie, hetgeen verrassend is omdat er juist veel onderzoek is gedaan naar leeftijdsvooroordelen (zie bijvoorbeeld Palmore, 2015).

Onze resultaten laten zien dat jong-volwassenen met vrienden boven de 70 , en ouderen met vrienden onder de 30 minderheidsgroepen zijn binnen hun respectieve leeftijdsgroepen: 18\% van de jongeren en 31\% van de ouderen in de 25 Europese landen in ons onderzoek rapporteren twee of meer leeftijdsheterogame vriendschappen. Deze resultaten onderschrijven de leeftijdssegregatie die kenmerkend is voor onze samenleving (Hagestad \& Uhlenberg, 2005): nauwe banden tussen oud en jong zijn relatief schaars. De lagere prevalentie van leeftijdsheterogame vriendschappen onder jongeren dan onder ouderen komt overeen met recente gegevens uit de Verenigde Staten. Smith, McPherson en Smith-Lovin (2014) tonen aan dat Amerikaanse jongeren in toenemende mate in zogenaamde leeftijdshomogame getto's leven. 
Niet alleen benoemen jongeren vaker dan ouderen hun leeftijdgenoten als vertrouwenspersonen, maar het verschil is in de onderzochte periode (1985-2004) toegenomen. Dat jongeren in toenemende mate in afzondering leven van oudere leeftijdsgroepen wordt door de auteurs toegeschreven aan uitstel van levenslooptransities zoals toetreding tot de arbeidsmarkt, huwelijk en ouderschap. Uitstel heeft weer te maken met onzekerheid over de eigen toekomst.

In overeenstemming met het ontmoetingsbeginsel, laten onze resultaten zien dat jongeren en ouderen die in omgevingen buiten de familie komen waar er mogelijkheden zijn voor betekenisvol intergenerationeel contact vaker leeftijdsheterogame vriendschappen hebben. Voorbeelden van dergelijke omgevingen zijn leeftijdsgeïntegreerde werkplekken (betaalde banen en vrijwilligersactiviteiten) en religieuze gemeenschappen. De resultaten laten ook zien, zoals verwacht, dat nauwe banden (gedeeld huishouden, vertrouwensrelatie) met familieleden die sterk in leeftijd verschillen voor jong-volwassenen mogelijkheden bieden voor het aangaan en onderhouden van leeftijdshetergame vriendschappen. Onder de oudere respondenten zien we dat nauwe banden met (klein)kinderen niet de kans vergroten dat betrokkenen vaker leeftijdsheterogame vriendschappen hebben. Nadere analyses tonen aan dat het uitblijven van het verwachte resultaat is toe te schrijven aan het opnemen van de gevoelens voor de jongere leeftijdsgroep in de analyses. We zien hier, weliswaar met cross-sectionele gegevens, aanwijzingen dat betekenisvolle contacten met jongere familieleden leiden tot meer positieve gevoelens over jongeren in het algemeen, die op hun beurt de kans op leeftijdsheterogame vriendschappen vergroten.

In overeenstemming met het dispositiebeginsel, laten onze resultaten zien dat degenen met meer positieve gevoelens voor de andere leeftijdsgroep vaker leeftijdsheterogame vriendschappen hebben. Natuurlijk hebben we hier een causaliteitsprobleem: de richting van de samenhang kan beide kanten oplopen. We kunnen niet ontrafelen of positieve gevoelens tot meer ontvankelijkheid leiden voor relaties met mensen uit andere leeftijdsgroepen of dat het hebben van intergenerationele relaties juist tot meer positief denken leidt over mensen die sterk in leeftijd verschillen. De verwachting dat naar leeftijd gemêleerde omgevingen een nog sterkere basis zouden vormen voor het aangaan van leeftijdsheterogame vriendschappen voor mensen met meer positieve gevoelens voor andere leeftijdsgroepen, vindt geen empirische steun. Het lijkt erop dat omgevingsbeginsel en dispositiebeginsel ieder apart, en niet in samenhang, een bijdrage leveren aan de verklaring van leeftijdsheterogame vriendschappen.

Onze resultaten laten zien dat determinanten op het individuele niveau sterker samenhangen met de kans dat mensen vriendschappen onderhouden met personen die veel ouder of jonger zijn dan zijzelf dan determinanten op het landniveau. Noch de Active Ageing Index, onze indicator voor macro-structurele omstandigheden, noch vertrouwen en individualisme, onze indicatoren voor cultureel klimaat, blijken significant samen te hangen met de kans om leeftijdsheterogame vriendschappen te onderhouden. Blijkbaar is de deelname aan activiteiten in omgevingen waar jong en oud samenkomen de cruciale factor voor de bevordering van vruchtbare intergenerationele contacten. In een eerdere studie is aangetoond dat dergelijke omgevingen vaker voorkomen in landen die hoog scoren op de Active Ageing Index (Dykstra \& 
Fleischmann, te verschijnen). Hier zien we ook het belang van gedecentraliseerde initiatieven gericht op meer contact en samenwerking tussen mensen van verschillende leeftijdsgroepen, zogenaamde intergenerationele projecten (Penninx, 2012). Het belang van lokale initiatieven is ook naar voren gekomen in een Eurobarometer survey uit 2009 over intergenerationele solidariteit. ${ }^{6}$ Volgens deze studie vindt de meerderheid van de inwoners van de lidstaten dat er onvoldoende mogelijkheden zijn voor oud en jong om elkaar te ontmoeten en met elkaar samen te werken via verenigingen en plaatselijke projecten. Voor een verbetering van de verstandhouding tussen oud en jong lijkt eerder een sleutelrol te zijn weggelegd voor lokale initiatieven dan voor nationale overheden. 


\section{Literatuur}

Abrams, J. R., Eveland,W. P., Jr., \& Giles, H. (2003). The effects of television on group vitality: Can television empower nondominant groups? In P. J. Kalbfleisch (Ed.), Communication Yearbook (Vol. 27, pp. 193-220). New York: Routledge.

Abrams, D., Lima, L., \& Coudin, G. (2007). Experiences and expressions of ageism. Question module design team (ESS round 4) application form. Retrieved on April 1, 2013 from http://www.europeansocialsurvey.org/index.php?option=com_docman\&task=cat_view\& gid $=48 \&$ Itemid $=80$

Ajrouch. K. J., Blandon, A., \& Antonucci, T. C. (2005). Social networks among men and women: The effects of age and socioeconomic status. Journal of Gerontology: Social Sciences, 60, 311-317.

Allik, J., \& Realo, A. (2004). Individualism-collectivism and social capital. Journal of CrossCultural Psychology, 35(1), 29-49.

Antonucci, T. C. (2001). Social relations: An examination of social networks, social support, and sense of control. In J. E. Birren \& K. W. Schaie (Eds.), Handbook of the psychology of aging ( $5^{\text {th }}$ ed., pp. 427-453). San Diego: Academic Press.

Binstock, R. H. (1983). The aged as a scapegoat. The Gerontologist, 23, 136-143.

Binstock, R. H. (2010). 50th anniversary feature article. From compassionate ageism to intergenerational conflict? The Gerontologist, 50, 574-585.

Blau, P. M. 1977. Inequality and geterogeneity: A primitive theory of social structure. New York: Free Press.

Butler, R. N. (1969). Age-ism: Another form of bigotry. The Gerontologist, 9 , 243-246.

Campbell, A. L., (2012). Policy makes mass politics. Annual Review of Political Science, 15, 333-351.

Coleman, J. S. (1982). The asymmetric society. Syracuse, NY: Syracuse University Press.

Delhey, J., \& Newton, K. (2005). Predicting cross-national levels of social trust: Global pattern or Nordic exceptionalism? European Sociological Review, 21, 311-327.

Dykstra, P. \& Fleischmann, M. (te verschijnen). Are societies with a high value on the Active Ageing Index more age-integrated? In A. Zaidi, S. Harper, K. Howse, G. Lamura, \& J. Perek-Białas, (Eds.), Building evidence for active ageing policies: Active Ageing Index and its potential. London: Palgrave Macmillan.

Evans, A. R. (2011). Now is the time: Seminaries responding to the graying of our congregations. Journal of Religion, Spirituality \& Aging, 23, 77-91.

Fischer, C. S. (1982). To dwell among friends: Personal networks in town and city. Chicago: University of Chicago Press.

Fischer, C. S., \& Oliker, S. (1983). A research note on friendship, gender, and the life cycle, Social Forces, 62, 124-132. 
Foster, L., \& Walker, A. (2015). Active and successful aging: A European policy perspective. The Gerontologist, 55, 83-90.

Grefe, D. (2011). Combating ageism with narrative and intergroup contact: Possibilities of intergenerational connections. Pastoral Psychology, 60, 99-105.

Hagestad, G. O. (2008). Changes in children's age and generation mosaics: Challenges to research and policy. In A. Leira \& C. Saraceno (Eds.), Childhood: Changing contexts (pp. 113-132). Comparative Social Research series, Vol. 25. Bingley, UK: Emerald.

Hagestad, G. O., \& Uhlenberg, P. (2005). The social separation of old and young: A root of ageism. Journal of Social Issues, 61, 343-60.

Hagestad, G. O., \& Uhlenberg, P. (2006). Should we be concerned about age segregation? Some theoretical and empirical explorations. Research on Aging, 28, 638-653

Harwood, J., Hewstone, M., Paolini, S., \& Voci, A. (2005). Grandparent-grandchild contact and attitudes toward older adults: Moderator and mediator effects. Personality and Social Psychology Bulletin, 31, 393-406.

Hofstede, G., Hofstede, G. J., \& Minkov, M. (2010). Culture and organizations. Software of the mind: Intercultural cooperation and its importance for survival. New York: McGraw Hill.

Huang, J., Maassen van den Brinka, H., Groot, W. (2009). A meta-analysis of the effect of education on social capital. Economics of Education Review, 28, 454-464

Huckfeldt, R.R. (1983). Social contexts, social networks, and urban neighborhoods:

Environmental constraints on friendship choice, American Journal of Sociology, 89, 651669.

Huston, T.L., \& Levinger, G. (1978). Interpersonal attraction and relationships. Annual Review of Psychology, 29, 115-56.

Ius Laboris (2010). Age discrimination in Europe: A reference guide. Global Human Resource Lawyers. http://www.iuslaboris.com/files/documents/Public

Files/Publications/2010_Publications/Age-Discrimination-in-Europe.pdf.

Kessler, E. M., Rakoczy, K. \& Staudinger, U. M. (2004). The portrayal of older people in prime time television series: The match with gerontological evidence. Ageing \& Society, 24, 531-552.

Kohli, M. (1988). Social organization and subjective construction of the life course. In A. B. Sorensen, F. E. Weiner, \& L. R. Sherrod (Eds.), Human development and the life cycle (pp. 271-292). Hillsdale, NJ: Erlbaum.

Kohli, M. (2007). The institutionalization of the life course: Looking back to look ahead. Research in Human Development, 4, 253-271.

Lahey, J. N. (2010). International comparison of age discrimination laws. Research on Aging, 32, 679-697.

Laumann, E. O. (1973). Bonds of pluralism: The form and substance of urban social networks. New York: Wiley. 
Lazarsfeld, P. F., \& Merton, R. K. (1954). Friendship as social process: A substantive and methodological analysis. In M. Berger, T. Abel, \& C. H. Page (Eds.), Freedom and control in modern society (pp. 18-66). Van Nostrand, New York,.

Lepianka, D. (2015). How similar, how different? On Dutch media depictions of older and younger people. Ageing \& Society, 35, 1095-1113.

Liefbroer, A. C., \& Billari, F. C. (2010). Bringing norms back in: A theoretical and empirical discussion of their importance for understanding demographic behaviour. Population, Space and Place, 16, 287-305.

Lynch, J. (2006). Age in the welfare state: The origins of social spending on pensioners, workers, and children (Cambridge Studies in Comparative Politics). Cambridge, UK: Cambridge University Press.

Mayer, K.U., \& Müller W. (1986). The state and the structure of the life course. In A. B. Sørensen, F. E. Weinert \& L. R. Sherrod (Eds.), Human development and the life course: Multidisciplinary perspectives (pp. 217-246). Hillsdale, NJ: Erlbaum.

Mayer, K. U., \& Schöpflin, U. (1989). The state and the life course. Annual Review of Sociology, 15, 187-209.

McPherson, M., Smith-Lovin, L., \& Cook, J. M. (2001). Birds of a feather: Homophily in social networks. Annual Review of Sociology, 27, 415-444.

Mollenhorst, G., Völker, B., \& Flap, H. (2008). Social contexts and core discussion networks: Using a choice-constraint approach to study similarity in intimate relationships. Social Forces, 86, 937-965.

Palmore, E. (2015). Ageism comes of age: Editorial. Journals of Gerontology: Social Sciences, $70,873-875$.

Penninx, K. (2012). Intergenerationeel werken: Bruggen bouwen tussen generaties in de wijk. In E. Messelius \& A. van Assel (Red.), Leren niet verleren: Voor wie ouderen wil ondersteunen bij leven (pp. 161-168). Apeldoorn: Garant.

Pettigrew, T. F. (1998). Intergroup contact theory. Annual Review of Psychology, 47, 65-85.

Pettigrew, T. F. \& Tropp, L. R. (2006). A Metaanalytic test of intergroup contact theory. Journal of Personality and Social Psychology, 90, 751-783.

Riley, M. W., \& Riley, J. W., Jr. (1994). Age integration and the lives of older people. The Gerontologist, 34, 110-115.

Riley, M. W., \& Riley, J. W. Jr. (2000). Age integration: Conceptual and historical background. The Gerontologist, 40, 266-270.

Rippon, I., Zaninotto, P. \& Steptoe, A. (2015). Greater perceived age discrimination in England than the United States: Results from HRS and ELSA. Journals of Gerontology: Social Sciences, 70, 925-933.

Roy, A., \& Harwood, J. (1997). Underrepresented, positively portrayed: Older adults in television commercials. Journal of Applied Communication Research, 25, 35-56. 
Settersten, R. A., Jr., \& Hagestad, G. O. (1996a). What's the latest? Cultural age deadlines for family transitions. The Gerontologist, 36, 178-188.

Settersten, R. A., Jr., \& Hagestad, G. O. (1996b). What's the latest? II. Cultural age deadlines for educational and work transitions. The Gerontologist, 36, 602-613.

Smith, K. P., \& Christakis, N. A. (2008). Social networks and health. Annual Review of Sociology, 34, 405-429.

Smith, J. A., McPherson, M., \& Smith-Lovin, L. (2014). Social distance in the United States: Sex, race, religion, age, and education homophily among confidants, 1985 to 2004. American Sociological Review, 79, 432-456.

Spéder, Z., Murinkó, L., \& Settersten, R. A., Jr. (2014). Are conceptions of adulthood universal and unisex? Ages and social markers in 25 European countries. Social Forces, 92, 873898.

Tam, T., Hewstone, M., Harwood, J., Voci, A., \& Kenworthy, J. (2006). Intergroup contact and grandparent-grandchild communication: The effects of self-disclosure on implicit and explicit biases against older people. Group Processes \& Intergroup Relations, 9, 413429.

Townsend, P. (2006). 25th volume celebration paper. Policies for the aged in the 21st century: More 'structured dependency' or the realisation of human rights? Ageing and Society, 26, 161-179.

Uhlenberg, P. (2000). Why study age integration? The Gerontologist, 40, 276-81.

Uhlenberg, P., \& De Jong Gierveld, J. (2004). Age-segregation in later life: An examination of personal networks. Ageing and Society, 24, 5-28.

UNECE/ European Commission (2015). Active Ageing Index 2014: Analytical report, Report prepared by Asghar Zaidi of the Centre for Research on Ageing, University of Southampton and David Stanton, under contract with United Nations Economic Commission for Europe (Geneva), co-funded by European Commission's Directorate General for Employment, Social Affairs and Inclusion (Brussels).

Vanderbeck, R. M. (2007). Intergenerational geographies: Age relations, segregation and reengagements. Geography Compass, 1/2, 200-221.

Van Tilburg, T. (1995). Delineation of the social network and differences in network size. In C. P. M. Knipscheer, J. de Jong Gierveld, T. G. van Tilburg, \& P. A. Dykstra (Eds.), Living arrangements and social networks of older adults (pp. 83-96). Amsterdam: VU University Press.

Verbrugge, L. M. (1977). The structure of adult friendship choices. Social Forces, 56, 576-97. Walker, A. (2000). Public policy and the construction of old age in Europe. The Gerontologist, 40, 304-308.

Zaidi, A., K. Gasior, M. M. Hofmarcher, O. Lelkes, B. Marin, R. Rodrigues, A. Schmidt, P. Vanhuysse and E. Zolyomi (2013). Active Ageing Index 2012: Concept, Methodology and Final Results. EC/UNECE, Active Ageing Index Project, UNECE Grant 
ECE/GC/2012/003, European Centre for Social Welfare Policy and Research, Vienna. http://www.euro.centre.org/data/aai/1253897823_70974.pdf

Zhang, Y. B., Harwood, J., Williams, A., Ylanne-McEwen, V., Wadleigh, P. M. \& Thimm, C. (2006). The portrayal of older adults in advertising: A cross-national review. Journal of Language and Social Psychology, 25, 264-282. 
Tabel 1. Beschrijvende kenmerken: Determinanten op het individuele niveau

\begin{tabular}{|c|c|c|c|c|c|}
\hline Omgevingsfactoren & & \multicolumn{2}{|c|}{$\begin{array}{l}\text { Leeftijd 18-30 } \\
\qquad(\mathrm{N}=8560)\end{array}$} & \multicolumn{2}{|c|}{$\begin{array}{l}\text { Leeftijd 70-90 } \\
\quad(\mathrm{N}=6411)\end{array}$} \\
\hline Heeft huisgenoot $>70[<30]$ & $0 / 1$ & \multicolumn{2}{|l|}{0,04} & \multicolumn{2}{|l|}{0,03} \\
\hline $\begin{array}{l}\text { Bespreekt persoonlijke kwesties } \\
\text { met familielid }>70 \text { [met } \\
\text { (klein)kind] }\end{array}$ & $0 / 1$ & \multicolumn{2}{|l|}{0,58} & \multicolumn{2}{|l|}{0,64} \\
\hline $\begin{array}{l}\text { Woont ten minste maandelijks } \\
\text { religieuze diensten bij }\end{array}$ & $0 / 1$ & \multicolumn{2}{|l|}{0,18} & \multicolumn{2}{|l|}{0,42} \\
\hline $\begin{array}{l}\text { Heeft de afgelopen maand } \\
\text { betaald werk of vrijwilligerswerk } \\
\text { verricht }\end{array}$ & $0 / 1$ & \multicolumn{2}{|l|}{0,64} & \multicolumn{2}{|l|}{0,12} \\
\hline $\begin{array}{l}\text { Werkte met collega's of collega- } \\
\text { vrijwilligers }>70[<30]\end{array}$ & $0 / 1$ & \multicolumn{2}{|l|}{0,08} & \multicolumn{2}{|l|}{0,04} \\
\hline \multicolumn{6}{|l|}{ Dispositie } \\
\hline $\begin{array}{l}\text { Positieve gevoelens voor mensen } \\
\text { ouder dan } 70 \text { [20ers] }\end{array}$ & $0-10$ & 7,36 & 1,89 & 6,87 & 2,06 \\
\hline \multicolumn{6}{|l|}{ Controlevariabelen } \\
\hline Geslacht (vrouw $=1)$ & $0 / 1$ & 0,52 & & 0,59 & \\
\hline Leeftijd & $\begin{array}{l}18-30 \\
{[70-90]}\end{array}$ & 24,27 & 3,72 & 76,51 & 5,03 \\
\hline Opleiding & $\begin{array}{l}0-25 \\
{[0-26]}\end{array}$ & 13,41 & 2,96 & 9,26 & 4,45 \\
\hline Woont samen met partner & $0 / 1$ & 0,33 & & 0,47 & \\
\hline Gezondheid & $0-4$ & 3,25 & 0,74 & 2,06 & 0,96 \\
\hline
\end{tabular}


Tabel 2. Beschrijvende kenmerken: Determinanten op het landniveau.

\begin{tabular}{|c|c|c|c|c|}
\hline Land & $\begin{array}{l}\text { Active Ageing } \\
\text { Index }\end{array}$ & $\begin{array}{l}\text { BBP per capita in } \\
\text { koopkracht pariteit } \\
\text { (gecentreerd rond } \\
\text { EU-28 } \\
\text { gemiddelde) }\end{array}$ & $\begin{array}{l}\text { Vertrouwen, } \\
\text { geaggregeerd }\end{array}$ & $\begin{array}{c}\text { Individualisme, } \\
\text { geaggregeerd }\end{array}$ \\
\hline België & 32,4 & 14 & 5,13 & 3,10 \\
\hline Bulgarije & 26,9 & -56 & 3,43 & 2,77 \\
\hline Cyprus & 32,4 & 5 & 4,58 & 3,25 \\
\hline Denemarken & 38,8 & 23 & 6,92 & 3,02 \\
\hline Duitsland & 34,3 & 16 & 4,84 & 2,98 \\
\hline Estland & 33,4 & -32 & 5,44 & 2,80 \\
\hline Finland & 36,9 & 20 & 6,45 & 2,76 \\
\hline Frankrijk & 33,0 & 6 & 4,45 & 2,87 \\
\hline Griekenland & 28,7 & -6 & 3,92 & 3,54 \\
\hline Hongarije & 26,3 & -37 & 4,15 & 3,28 \\
\hline Ierland & 35,8 & 32 & 5,45 & 3,06 \\
\hline Kroatië & 28,3 & -37 & 4,17 & 2,79 \\
\hline Letland & 32,2 & -40 & 4,12 & 3,27 \\
\hline Litouwen & 30,1 & -37 & 4,41 & 2,58 \\
\hline Nederland & 38,6 & 39 & 5,89 & 3,08 \\
\hline Oostenrijk & 31,3 & 24 & 5,45 & 3,16 \\
\hline Polen & 27,0 & -46 & 4,17 & 2,85 \\
\hline Portugal & 32,3 & -21 & 3,65 & 2,71 \\
\hline Roemenië & 29,4 & -52 & 3,79 & 3,04 \\
\hline Slovenië & 30,0 & -11 & 4,32 & 3,27 \\
\hline Slowakije & 26,8 & -28 & 3,99 & 2,83 \\
\hline Spanje & 30,4 & 2 & 4,90 & 2,92 \\
\hline Tsjechische Republiek & 31,0 & -19 & 4,67 & 2,90 \\
\hline Verenigd Koninkrijk & 38,0 & 14 & 5,27 & 2,93 \\
\hline Zweden & 42,6 & 26 & 6,35 & 2,88 \\
\hline Totaal & 32,3 & EU-28: $100(0)$ & 4,79 & 2,98 \\
\hline
\end{tabular}

Noot. Per kolom: laagste landwaarde in schuin, hoogste landwaarde in vet. 
Tabel 3. Beschrijvende kenmerken: Prevalentie per land van het hebben van twee of meer leeftijdsheterogame vriendschappen

\begin{tabular}{lll}
\hline & $\geq 2$ leeftijdsheterogame vriendschappen \\
\cline { 2 - 3 } & Leeftijd 18-30 & Leeftijd 70-90 \\
Land & \% 10560$)$ & $(\mathrm{N}=6375)$ \\
\hline België & 20,6 & $\%$ \\
Bulgarije & 13,6 & 29,8 \\
Cyprus & 9,4 & 22,4 \\
Denemarken & 13,4 & 28,9 \\
Duitsland & 29,0 & 26,7 \\
Estland & 15,8 & 40,0 \\
Finland & 20,9 & 32,5 \\
Frankrijk & 19,6 & $\mathbf{5 0 , 5}$ \\
Griekenland & 14,0 & 30,4 \\
Hongarije & 14,3 & 26,6 \\
Ierland & $\mathbf{3 6 , 3}$ & 16,2 \\
Kroatië & 13,2 & 43,9 \\
Letland & 16,9 & 27,6 \\
Litouwen & 4,0 & 22,4 \\
Nederland & 8,5 & 5,1 \\
Oostenrijk & 11,7 & 17,9 \\
Polen & 16,0 & 22,5 \\
Portugal & 36,1 & 35,4 \\
Roemenië & 20,2 & 42,0 \\
Slovenië & 21,1 & 29,7 \\
Slowakije & 18,0 & 34,7 \\
Spanje & 18,8 & 28,5 \\
Tsjechische Republiek & 17,2 & 22,5 \\
Verenigd Koninkrijk & 27,9 & 29,8 \\
Zweden & 18,5 & 38,9 \\
\hline Totaal & 18,2 & 47,3 \\
\hline Noor Per kolo & 31,0 \\
\hline
\end{tabular}

Noot. Per kolom: laagste landwaarde schuin, hoogste landwaarde vet. 
Tabel 4. Multiniveau logistische regressie voor leeftijdsheterogame vriendschappen, determinanten op het individuele niveau, uitgevoerd voor 25 landen

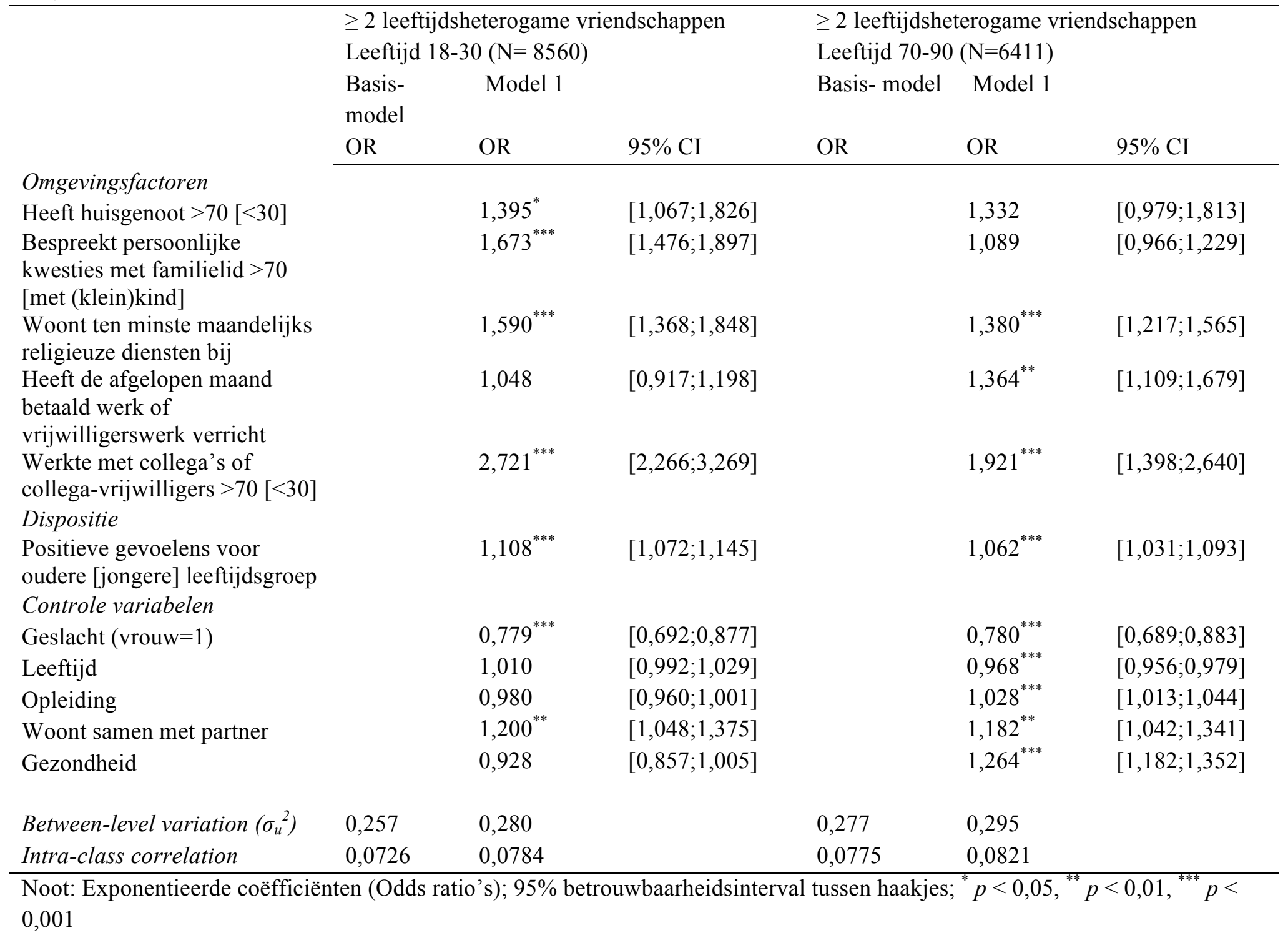


Tabel 5. Multiniveau logistische regressie voor leeftijdsheterogame vriendschappen, determinanten op het landniveau rekening houdend met de individuele determinanten uit Model 1 (Tabel 4), uitgevoerd voor 25 landen

\begin{tabular}{|c|c|c|c|c|c|c|}
\hline & \multicolumn{3}{|c|}{$\begin{array}{c}\geq 2 \text { leeftijdsheterogame vriendschappen } \\
\text { Leeftijd 18-30 }(\mathrm{N}=8560)\end{array}$} & \multicolumn{3}{|c|}{$\begin{array}{c}\geq 2 \text { leeftijdsheterogame vriendschappen } \\
\text { Leeftijd } 70-90(\mathrm{~N}=6411)\end{array}$} \\
\hline & Model 2 & Model 3 & Model 4 & Model 2 & Model 3 & Model 4 \\
\hline & $\begin{array}{c}\mathrm{OR} \\
{[95 \% \mathrm{CI}]}\end{array}$ & $\begin{array}{c}\text { OR } \\
{[95 \% \mathrm{CI}]}\end{array}$ & $\begin{array}{c}\text { OR } \\
{[95 \% \mathrm{CI}]}\end{array}$ & $\begin{array}{c}\text { OR } \\
{[95 \% \mathrm{CI}]}\end{array}$ & $\begin{array}{c}\mathrm{OR} \\
{[95 \% \mathrm{CI}]}\end{array}$ & $\begin{array}{c}\text { OR } \\
{[95 \% \mathrm{CI}]}\end{array}$ \\
\hline \multicolumn{7}{|l|}{$\begin{array}{l}\text { Gecontroleerd voor } \\
\text { individueel niveau }\end{array}$} \\
\hline $\begin{array}{l}\text { Active Ageing Index } \\
\text { (gecentreerd) }\end{array}$ & $\begin{array}{c}1,017 \\
{[0,973 ; 1,063]}\end{array}$ & & & $\begin{array}{c}1,035 \\
{[0,990 ; 1,082]}\end{array}$ & & \\
\hline $\begin{array}{l}\text { Vertrouwen } \\
\text { (geaggregeerd) }\end{array}$ & & $\begin{array}{c}0,790 \\
{[0,552 ; 1,132]}\end{array}$ & & & $\begin{array}{c}1,028 \\
{[0,700 ; 1,509]}\end{array}$ & \\
\hline $\begin{array}{l}\text { Individualisme } \\
\text { (geaggregeerd) } \\
\text { Controlevariabele }\end{array}$ & & & $\begin{array}{c}0,927 \\
{[0,341 ; 2,521]}\end{array}$ & & & $\begin{array}{c}0,630 \\
{[0,227 ; 1,746]}\end{array}$ \\
\hline $\begin{array}{l}\text { BBP per capita in } \\
\text { koopkracht pariteit } \\
\text { (gecentreerd rond } \\
\text { EU-28 gemiddelde) }\end{array}$ & $\begin{array}{c}1,000 \\
{[0,988 ; 1,012]}\end{array}$ & $\begin{array}{c}1,009 \\
{[0,998 ; 1,021]}\end{array}$ & $\begin{array}{c}1,004 \\
{[0,996 ; 1,011]}\end{array}$ & $\begin{array}{c}0,995 \\
{[0,984 ; 1,007]}\end{array}$ & $\begin{array}{c}1,002 \\
{[0,990 ; 1,014]}\end{array}$ & $\begin{array}{c}1,003 \\
{[0,996 ; 1,011]}\end{array}$ \\
\hline $\begin{array}{l}\text { Between-level } \\
\text { variation }\left(\sigma_{u}^{2}\right)\end{array}$ & 0,260 & 0,249 & 0,267 & 0,258 & 0,289 & 0,276 \\
\hline $\begin{array}{l}\text { Intra-class } \\
\text { correlation }\end{array}$ & 0,0734 & 0,0704 & 0,0752 & 0,0728 & 0,0808 & 0,0772 \\
\hline
\end{tabular}

Noot. Geëxponentieerde coëfficiënten (Odds ratio's); 95\% betrouwbaarheidsinterval tussen haakjes; ${ }^{*} p<0,05,{ }^{* * *} p<0,01$, ${ }^{* * *} p<0,001$. 


\section{Eindnoten}

1. Beide auteurs zijn verbonden aan de afdeling Bestuurskunde en Sociologie van de Erasmus Universiteit Rotterdam, Postbus 1738, 3000 DR Rotterdam. Pearl Dykstra (email: dykstra@fsw.eur.nl) is hoogleraar Empirische Sociologie, lid van de Koninklijke Nederlandse Akademie van Wetenschappen en lid van de High Level Group van wetenschappers die het College van Europese Commissarissen adviseert. Haar publicaties richten zich op intergenerationele solidariteit, veranderingen in families, en de levensloop. Maria Fleischmann (email: fleischmann@fsw.eur.nl) is postdoctoraal onderzoeker en universitair docent. Haar onderzoek richt zich op langer doorwerken, pensionering en de inzetbaarheid van werknemers van alle leeftijden.

2. Financiële steun voor het werk van de eerste auteur is afkomstig van de European Research Council Advanced Investigator Grant (ERC, 324211) 'Families in Context'. Financiële steun voor het werk van de tweede auteur komt van de NWO-TOP subsidie 'Sustaining employability' (NWO, 407-13-021). Een eerdere versie van dit paper is gepresenteerd tijdens het 2015 Active Ageing Index International Seminar in Brussel.

3. De paragraaf over hypothesen leunt sterk op een eerdere publicatie (Dykstra \& Fleischmann, te verschijnen).

4. http://ec.europa.eu/archives/ey2012/ (24/1/2016)

5. http://www1.unece.org/stat/platform/pages/viewpage.action?pageId=76287845 (5/1/2016)

6. ec.europa.eu/social/BlobServlet?docId=5693\&langId=en (14/1/2016) 